\title{
Structural-hydraulic test of the liquid metal EURISOL target mock-up
}

\author{
Rade Ž. Milenković $^{\mathrm{a}, *}$, Sergejs Dementjevs ${ }^{\mathrm{a}}$, Karel Samec ${ }^{\mathrm{a}}$, Ernests Platacis ${ }^{\mathrm{b}}$, Anatolij Zik ${ }^{\mathrm{b}}$, \\ Aleksej Flerov ${ }^{b}$, Enzo Manfrin ${ }^{a}$, Knud Thomsen ${ }^{a}$ \\ a Paul Scherrer Institut, $\mathrm{CH}-5232$ Villigen PSI, Switzerland \\ ${ }^{\mathrm{b}}$ Institute of Physics of the University of Latvia, LV-2156 Salaspils, Latvia
}

\section{A R T I C L E I N F O}

Article history:

Received 2 March 2009

Received in revised form 4 May 2009

Accepted 6 May 2009

\section{Keywords:}

Spallation target

Liquid metal

CFD

Structural acceleration

Cavitation

Advanced time-frequency analysis

MEGAPIE

EURISOL

\begin{abstract}
A B S T R A C T
Structural-hydraulic tests of the European Isotope Separation On-Line (EURISOL) neutron converter target mock-up, named MErcury Target EXperiment 1 (METEX 1), have been conducted by Paul Scherrer Institut (PSI, Switzerland) in cooperation with Institute of Physics of the University of Latvia (IPUL, Latvia). PSI proceeded with extensive thermal-hydraulic and structural computational studies, followed by the target mock-up tests carried out on the mercury loop at IPUL.

One of the main goals of the METEX 1 test is to investigate the hydraulic and structural behaviour of the EURISOL target mock-up for various inlet flow conditions (i.e. mass flow rates) and, in particular, for nominal operating flow rate and pressure in the system. The experimental results were analysed by advanced time-frequency methods such as Short-Time Fourier Transform in order to check the vibration characteristics of the mock-up and the resonance risk. The experimental results (obtained in METEX 1), which include inlet flow rate, pressure of the cover gas, total pressure loss, structural acceleration, sound and strain data, were jointly analysed together with numerical data obtained from Computational Fluid Dynamics (CFD).
\end{abstract}

(c) 2009 Elsevier B.V. All rights reserved.

\section{Introduction}

Within the scope of the European Isotope Separation On-Line (EURISOL) Design Study [1], one of the main tasks assigned to PSI is to design and build a high-power Liquid Metal Target (LMT). The study of the thermal-hydraulics and structure mechanics has been carried out at Paul Scherrer Institut (PSI) using commercial Computational Fluid Dynamic (CFD) and Finite Element Method (FEM) codes. As the most delicate component of the lower target container is the Beam Entrance Window (BEW), it is necessary to demonstrate that the structural integrity of the window can be maintained under a variety of operational and accidental scenarios. Therefore, recent experience obtained during design of the Megawatt Pilot Experiment (MEGAPIE) liquid metal target for the SINQ-PSI neutron spallation source [5] was extensively used. It is of crucial importance to safety that the BEW is adequately cooled. In the EURISOL concept, as in the European Spallation Source (ESS), the horizontal target configuration had a marked influence on the design. Therefore, the main goal is to design the liquid metal target including the BEW, which will be cooled only by the main annular inlet flow. The thermal-hydraulic and structural performance of the target concept was optimised at PSI [2] and experimental investigations described in this paper were used to validate computational results. Hydraulic calcula-

\footnotetext{
* Corresponding author. Tel.: +41563104453.

E-mail address: rade.milenkovic@psi.ch (R.Ž. Milenković).
}

tions, including physical modelling of two-phase flow phenomena such as cavitation and free-surface flows, have been carried out by using the Computational Fluid Dynamic Code CFX 11.0 [6]. These calculations have been accompanied by structural calculations performed with ANSYS 11.0 [3].

The main goal of MErcury Target EXperiment, stage 1 (METEX 1 ) is to investigate the hydraulic and structural behaviour of the target mock-up for various inlet flow conditions (i.e. mass flow rates and pressures in the system) and for two geometrical configurations (with and without flow vanes at the target Beam Entrance Window, Fig. 1). The total hydraulic pressure loss in the mock-up, the pressure of the cover gas in the expansion tank, the acceleration of the mock-up and of the loop filled with mercury, the fluid temperatures at the mock-up inlet and outlet, the mass flow rate and the strain at various locations were all measured. Due to wetting problems, the axial velocity measurements originally planned could not be conducted. The test results reported here were obtained with and without flow vanes.

The mock-up of the target designed and built at PSI was tested on the Institute of Physics of the University of Latvia (IPUL, Latvia) mercury loop. The measuring and data acquisition systems were prepared by PSI.

\section{The experiment}

The IPUL mercury loop has DN100 piping assembled in a vertical plane on a frame (Fig. 4, right). The target mock-up 


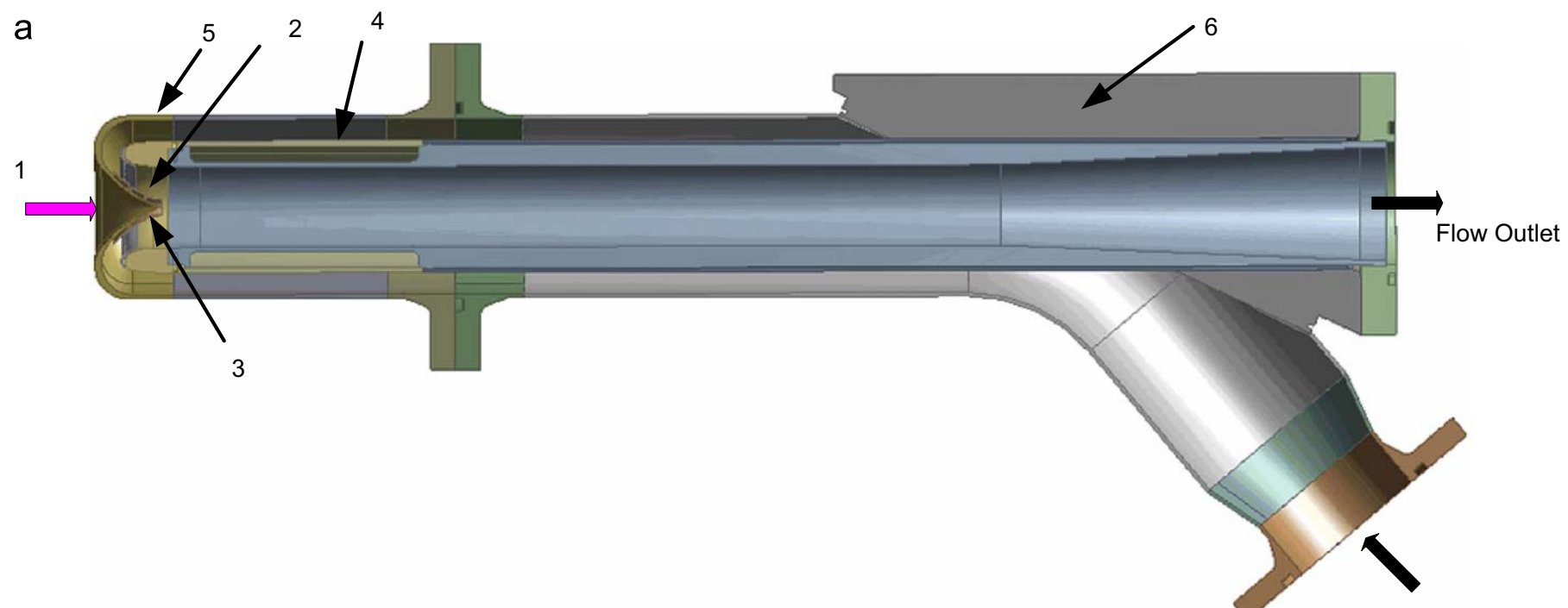

Flow Inlet
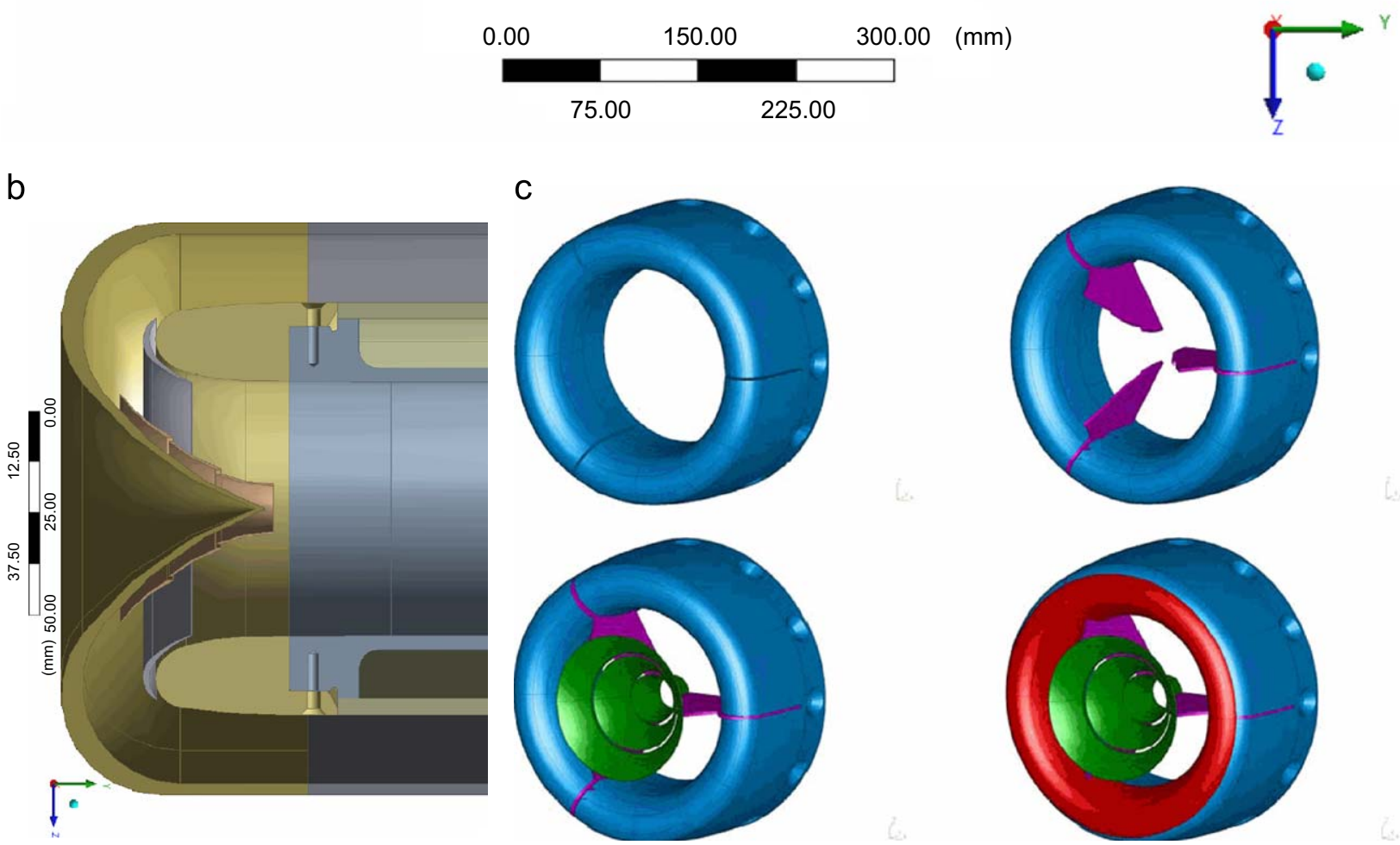

Fig. 1. (a) Cross-section of the EURISOL converter target: 1—proton beam; 2-flow vanes; 3-beam entrance window (BEW); 4-guide tube (GT); 5-liquid metal hull (LMH); 6-frame; (b) and (c) flow vanes.

(Fig. 4, left) was connected to the loop interface flanges. The target attachment flanges were fixed rigidly on a support, which stands on the Mercury laboratory floor, rather than to the frame, in order to minimize vibrations during operation of the loop.

Three acceleration sensors (KISTLER 8632C5) were fixed onto the target mock-up to measure vibrations at the outlet interface flange (AS1, vertical component of the acceleration) and on the target window (AS2 and AS3, vertical and horizontal components).

The loop was equipped with an electromagnetic pump (pos. 3), which could provide a liquid metal flow rate of up to $11.5 \mathrm{l} / \mathrm{s}$.

The loop contained a conduction-type electromagnetic flow meter (pos. 4). Prior to the test, the flow meter was calibrated against a Venturi tube, yielding a relative error of the measurements of $3 \%$ of the maximum flow rate $(11.5 \mathrm{l} / \mathrm{s})$. There was no automatic control system in the loop. The mercury flow rate was adjusted and maintained manually with an autotransformer in the pump electrical feed.

A differential manometer (DM, YOKOGAWA EJA110, see Fig. 2) was connected to the loop near the inlet and outlet flanges to measure the hydraulic pressure loss in the target mock-up, relative error is about $2 \%$ of the full range ( 2.5 bar).

During the pump operation, up to $40 \mathrm{~kW}$ of thermal power was dissipated in the mercury. There were four cooling water jackets on the stainless steel piping (pos. 5), which serve to remove the heat deposited by the electromagnetic pump. All the heat exchangers were regulated manually by adjusting the cooling water flow rate. During the test, the mercury temperature in the loop was kept in a range from 3 to $36^{\circ} \mathrm{C}$. There were two 
thermocouples in the target inlet and outlet pipes to measure the mercury temperature.

Static pressure in the target mock-up was adjusted by the pressure of the cover gas in the expansion tank (pos. 6). The pressure was measured with a manometer (M, WIKA UT10). As there was a height difference of approximately $0.76 \mathrm{~m}$ between the mercury level in the expansion tank and the target, there was a minimum absolute static pressure of $1 \mathrm{bar}$ in the target. The static pressure in the expansion tank was varied in the range from 1 to 6.5 bar.

The pressure sensors and thermocouples were operated with National Instruments FIELDPOINT blocks. The signals were recorded with a frequency of about 1 sample per second. The acceleration sensors were connected to a digital LeCroy oscilloscope. The frequency of the data acquisition for the acceleration sensors was 5000 samples per second. All the data acquired during the test were collected in a single data base.

The total mass of the mock-up filled with mercury was $176 \mathrm{~kg}$.

\section{Test matrices}

The complete test campaign was separated into two sessions: testing the configuration without (first session) and with (second session) flow vanes. For these two configurations the total pressure loss, structural acceleration, emitted sound and strain were determined experimentally. Different test matrices for two configurations with and without flow vanes (Tables 1 and 2, respectively) were adopted for the analysis. The Cavitation Ca number is defined as $C a=\left(p_{\text {out }}-p_{\text {sat }}(t)\right) / \Delta p$, where $\Delta p$ is the pressure loss. The pressure loss is determined experimentally. The saturation pressure of mercury vapour is $1.696 \mathrm{~Pa}$ for $50^{\circ} \mathrm{C}$ [4]. The temperature of the liquid metal during the tests was kept in a range from 3 to $30^{\circ} \mathrm{C}$. The Reynolds number in Tables 1 and 2 refers to the annulus. The values of the Reynolds numbers in Tables 1 and 2 show that fully-developed turbulent flow prevailed in the annulus.
Initial computational studies for the configuration without flow vanes [7] indicated that incipient cavitation occurs at high flow rates and for a pressure of about 2 bar (a temperature of $50{ }^{\circ} \mathrm{C}$ was used in simulations). In the experiment at a flow rate of $101 / \mathrm{s}$ and a pressure of the cover gas of 2 bar, characteristic cavitation noise, which was also audible to the human ear, was identified as a crackling and sizzling sound and recorded by the microphone. As incipient cavitation may not be audible, this particular flow regime was considered as developed cavitation. The cavitation number was the lowest of all the cases in Table 1, i.e. only 1.46. The locations, where cavitation was expected to occur first, lie at the end of the guide tube, where the flow turns by $180^{\circ}$.

Similarly, initial computational studies for the flow configuration with flow vanes showed several possible cavitation regions: in the narrow gaps between the vanes (can be referred to as jet cavitation) and at the end of the guide tube and the outer flow vane, where the flow turns by $180^{\circ}$ (see Fig. 1 ) (can be referred to as wake cavitation). The first four flow conditions presented in Table 2 lie in a regime without cavitation.

In the experiments, even though no crackling and sizzling sound typical of developed cavitation was registered for these flow conditions, a clear tone starting at low flow rates, whose frequency and intensity rose with the flow rate, was detected. It is not clear whether this tone corresponds to a resonance frequency. The last two flow conditions lie in the regime of incipient or developed cavitation.

\section{Results and discussions}

\subsection{Pressure drop estimations and comparison with experimental} results

The total pressure drop in the mock-up was measured as well as calculated by using well-known empirical correlations and experimental data [9] for similar flow configurations. The

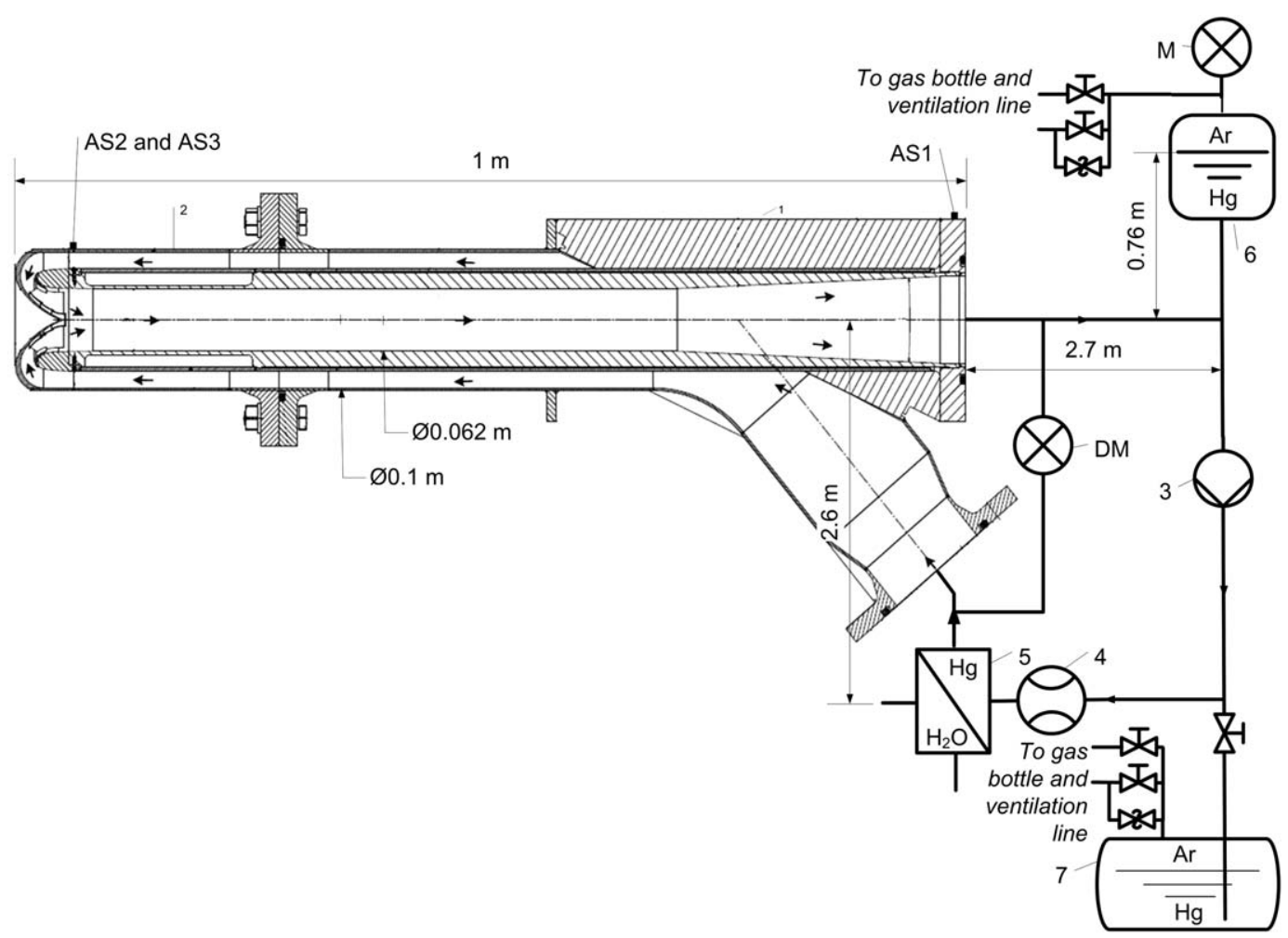

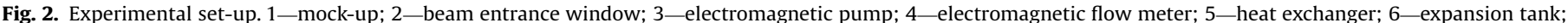
7-storage tank; M-manometer; DM—differential manometer; AS1, AS2 and AS3_acceleration sensors. 
Table 1

Test matrix and non-dimensional numbers for configuration without flow vanes (cover test conditions from 18.12.2008).

\begin{tabular}{|c|c|c|c|c|c|c|}
\hline Flow regime & Flow Rate (1/s) & $\begin{array}{l}\text { Outlet pressure } \\
\text { (bar) }\end{array}$ & $\begin{array}{l}\text { Pressure loss in the } \\
\text { mock-up (bar) }\end{array}$ & $\begin{array}{l}\text { Temperature at the } \\
\text { mock-up outlet }\left({ }^{\circ} \mathrm{C}\right)\end{array}$ & Re & $\mathrm{Ca}$ \\
\hline A1 & 4.44 & 2 & 0.29 & 9.91 & 221,700 & 6.99 \\
\hline A2 & 5.96 & 2 & 0.50 & 11.67 & 290,670 & 3.99 \\
\hline A3 & 7.28 & 2 & 0.75 & 13.73 & 359,643 & 2.67 \\
\hline A4 & 8.40 & 2 & 1.01 & 17.15 & 413,836 & 2.00 \\
\hline A5 & 9.23 & 2 & 1.20 & 19.88 & 458,175 & 1.68 \\
\hline A6 & 9.87 & 2 & 1.38 & 22.30 & 492,662 & 1.46 \\
\hline A7 & 10.23 & 2.74 & 1.50 & 25.45 & 442,662 & 1.82 \\
\hline A8 & 11.20 & 2.74 & 1.77 & 27.87 & 551,781 & 1.55 \\
\hline
\end{tabular}

Table 2

Test matrix and non-dimensional numbers for configuration with flow vanes (cover test conditions from 28.01.2009).

\begin{tabular}{|c|c|c|c|c|c|c|}
\hline Flow regime & Flow rate $(1 / s)$ & $\begin{array}{l}\text { Outlet pressure } \\
\text { (bar) }\end{array}$ & $\begin{array}{l}\text { Pressure loss in the } \\
\text { mock-up (bar) }\end{array}$ & $\begin{array}{l}\text { Temperature at the } \\
\text { mock-up outlet }\left({ }^{\circ} \mathrm{C}\right)\end{array}$ & $R e$ & $\mathrm{Ca}$ \\
\hline B1 & 3.73 & 5.313 & 0.258 & 6.92 & 183,763 & 20.6 \\
\hline B2 & 5.18 & 5.308 & 0.478 & 8.72 & 255,199 & 11.1 \\
\hline B3 & 6.32 & 5.308 & 0.703 & 11.58 & 311,362 & 7.57 \\
\hline B4 & 7.55 & 5.308 & 0.997 & 14.15 & 371,960 & 5.34 \\
\hline B5 & 8.55 & 5.534 & 1.293 & 17.64 & 421,326 & 4.16 \\
\hline B6 & 8.49 & 3.738 & 1.288 & 19.33 & 418,270 & 2.91 \\
\hline
\end{tabular}

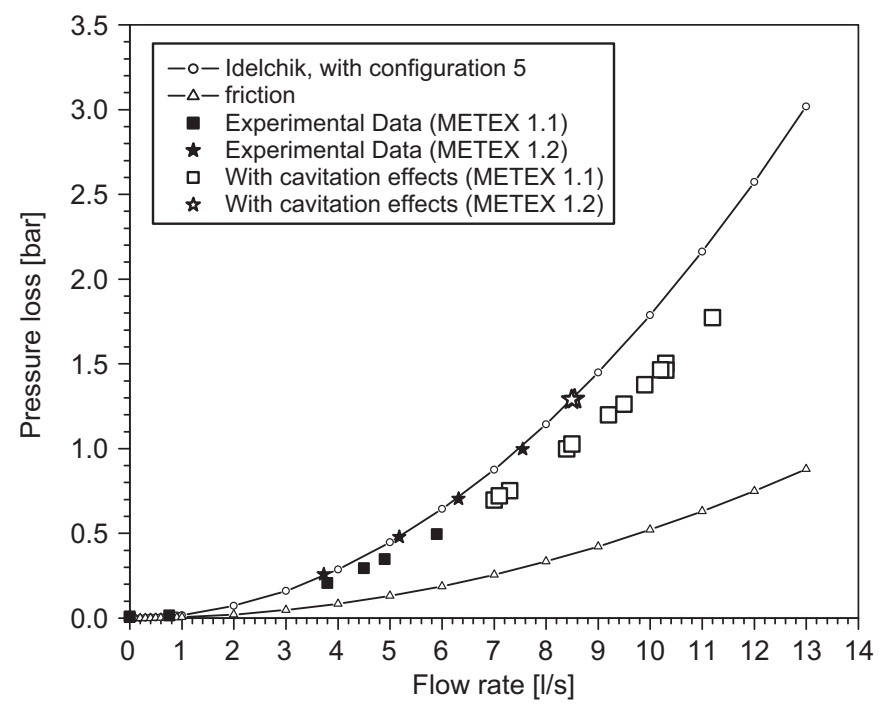

Fig. 3. Pressure loss in the target mock-up.

calculated pressure loss is directly compared with the experimental results in Fig. 3. Experimental data included results for both configurations, without and with flow vanes (referred to here as METEX 1.1 and METEX 1.2, respectively). Even though the configuration analysed ([9], configuration no. 5) does not exactly match those of our design, good agreement between the estimated and measured pressure losses was found. The experimental data were also used for the Cavitation number.

As already mentioned in Chapter 4, some experimental data presented in Fig. 3 lie in the regime of incipient or of developed cavitation. Therefore, the following conclusions are drawn:

- The pressure loss is essentially higher for the configuration with flow vanes. This conclusion is valid for flow regimes with and without cavitation; this result was expected from the CFD calculation which predicted an additional 0.2 bar with the flow vanes.
- The cavitation effects do not influence the pressure loss measurements because the data follow the well-established trend for regimes without cavitation. These regimes are marked with empty squares and stars in Fig. 3. For comparison, calculated pressure loss due to the friction in the target mockup is also presented in Fig. 3.

\subsection{Structural acceleration measurements}

The acceleration data were collected for no-flow and flow conditions with and without cavitation as well as for configurations with and without flow vanes. As the structural acceleration data carry information on coupled fluid-structure interactions, the main objectives are

- to estimate damping ratios and natural frequencies of the system,

- to detect indirectly the existence of large coherent structures (instabilities), which affect the structural behaviour,

- to detect any kind of resonance occurring during operation of the target,

- to check system integrity by comparing the signal characteristics for various flow conditions including no-flow,

- to detect incipient cavitation and to investigate the patterns in the time-frequency domain in case of developed cavitation.

The first test performed is a vibration test for the no-flow condition. It consisted of two essential parts: the noise acquisition and the damping test. The resulting data set was used for estimating the noise threshold level, i.e. for checking the level of the noise existing in the system. The locations of the acceleration sensors are presented in Fig. 4. The sensor connected to $\mathrm{CHO}$ was located at the BEW and measures horizontal acceleration of the mock-up whereas the sensor connected to $\mathrm{CH} 1$ was attached to the surface of the BEW and measures vertical acceleration. Sensor $\mathrm{CH} 2$ was attached to the loop at the outlet of the mock-up before the support.

The data set acquired during the vibration test for the no-flow condition is presented in Fig. 5a. It consisted of a noise and a 
dampened contribution, which were analysed separately. The dampened contribution resulted from the application of an external force (using a special hammer) to initiate vibrations. Based on acceleration measurements, the characteristics of the dampened sinusoidal such as frequencies and damping factor (see Fig. 5d and e, where Test 1 corresponds to Fig. 5a, whereas Test 2 and 3 are not shown here) were estimated using the Matrix Pencil Method. The normalized relative frequency distribution of the amplitudes is presented in Fig. 5b. The power spectrum shown in Fig. $5 \mathrm{c}$ reveals dominant frequencies, which characterize the system behaviour and can be compared with results obtained from modal analysis.

In order to search for the existence and behaviour of fluid-structure coupling in cases with flow, the ShortTime Fourier Transform (STFT) was applied on acceleration data samples. The results are compared in Figs. 6 and 7. The spectrograms (Hanning window 64 samples, 512 frequency bins and 8 time bins) of the acceleration signal $(\mathrm{CHO})$ visualize various flow regimes during operation of the mock-up. A vibrating component at $100 \mathrm{~Hz}$, which corresponds to the flow pulsations generated by the electromagnetic pump, can be clearly detected by the accelerometers for the configuration without flow vanes. In cavitation regimes strong bubble-structure interactions affect the vibrations of the mock-up, the clear $100 \mathrm{~Hz}$ component cannot be distinguished anymore. Furthermore, many peaks can be detected in the full frequency domain of the spectrograms in case of developed cavitation. In the spectrograms for the configuration with flow vanes (Fig. 7), the $100 \mathrm{~Hz}$ component cannot be clearly identified, but in the power spectrum (not presented here) for regime $\mathrm{B} 1$ it can be easily seen.

Spectrograms for selected regimes B1, B4 and B6 (configuration with flow vanes) reveal several resonance frequencies, for instance $1000 \mathrm{~Hz}$ in regime $\mathrm{B} 1$, which was also registered by the personnel in the laboratory. A whistling sound was also identified for flow regimes with developed cavitation. As the liquid metal flows through the narrow gaps of the flow vanes (see Fig. 8), the vortex shedding generated in jets for regimes without cavitation can produce a clear audible whistling sound and may cause the blades to resonate. The velocity field obtained from 3D Reynolds Averaged Navier-Stokes (RANS) simulations reveals critical regions (marked with arrows labelled as 1 and 2) in the flow field where naturally-developing instabilities and structures could be produced. Since the flow regime that occurs in the zone marked with a box can be referred to as a turbulent liquid jet, a periodic modulation of a coaxial liquid layer (see arrows 1 and 2 in Fig. 8) can generate periodically varying structures in the jet, which can be resonated with natural vibrations of the flow vanes and thus cause a positive feedback. More details about periodically excited single- and two-phase jets with controlled frequency and amplitude can be found in Milenković et al. [8].

Furthermore, at higher flow rates and lower pressure, jet cavitation can occur at the outlet of narrow gaps. As a broadband noise spectrum was found in the time-frequency domain, two basic cavitation phenomena (jet cavitation and wake cavitation) may occur. The enhancement of the magnitude of the STFT coefficients for regime B6 (Fig. 7) in the range between 500 and $750 \mathrm{~Hz}$ most probably indicate the existence of jet cavitation, because similar effects have not been registered for the configuration without flow vanes and for comparable flow regimes. Resonance phenomena shown in the spectrogram for regime B4 (Fig. 7) can cause failure of the flow vanes or the welds during the test. In order to further investigate these results, an analysis of sound measurements is presented in the next chapter.

The normalized relative frequency distribution of the acceleration is presented in Fig. 9. The maximum amplitudes do not exceed $2 \mathrm{~g}$ (which is below estimated allowable limits) during operation of the mock-up under turbulent flow conditions and/or developed cavitation. The $y$-axis is the normalized relative frequency of an acceleration (i.e. number of counts in an interval divided by the total number of counts and normalized by the interval width) and the $x$-axis is the centre value for each bin of the histogram. The total number of bins for all histograms was 100 . The plots (Fig. 9, left) show a higher level of white noise during the first test session as well as shifting of the signal during the acquisition time. Small shifting (marked as Direct Current (DC) level in Fig. 7) of the signal can be also seen in the histogram (Fig. 9 left) for regime B1.

Time-frequency analysis of structural acceleration under a variety of extreme operating conditions brought new insight, since even the weakest resonance frequencies of the structural vibrations can be clearly identified and localized in the time domain.

\subsection{Sound measurements}

The noise in the laboratory during operation of the mockup was acquired with a microphone connected to the personal computer. It was converted into an electric signal (voltage) and stored on the local hard disk at a rate of $22.5 \mathrm{kHz}$. The Short-Time Fourier Transform was applied on sound data samples. The results are compared in Figs. 10 and 11 for configurations with and
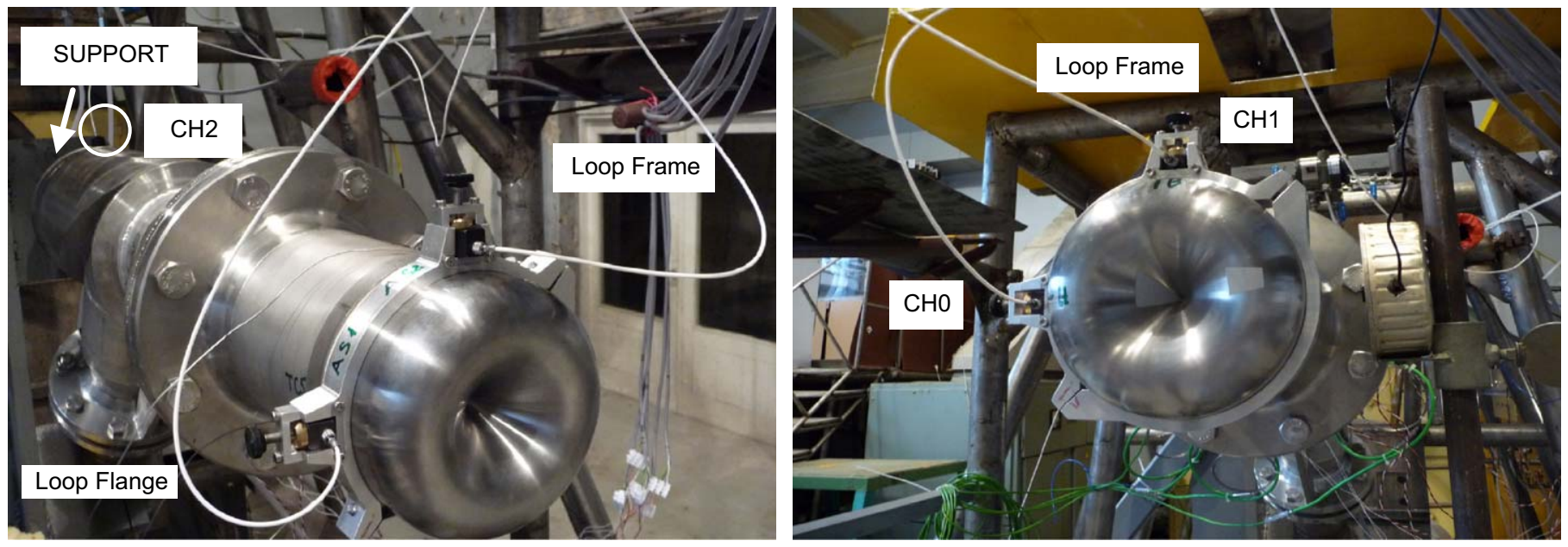

Fig. 4. Locations of the acceleration sensors. 

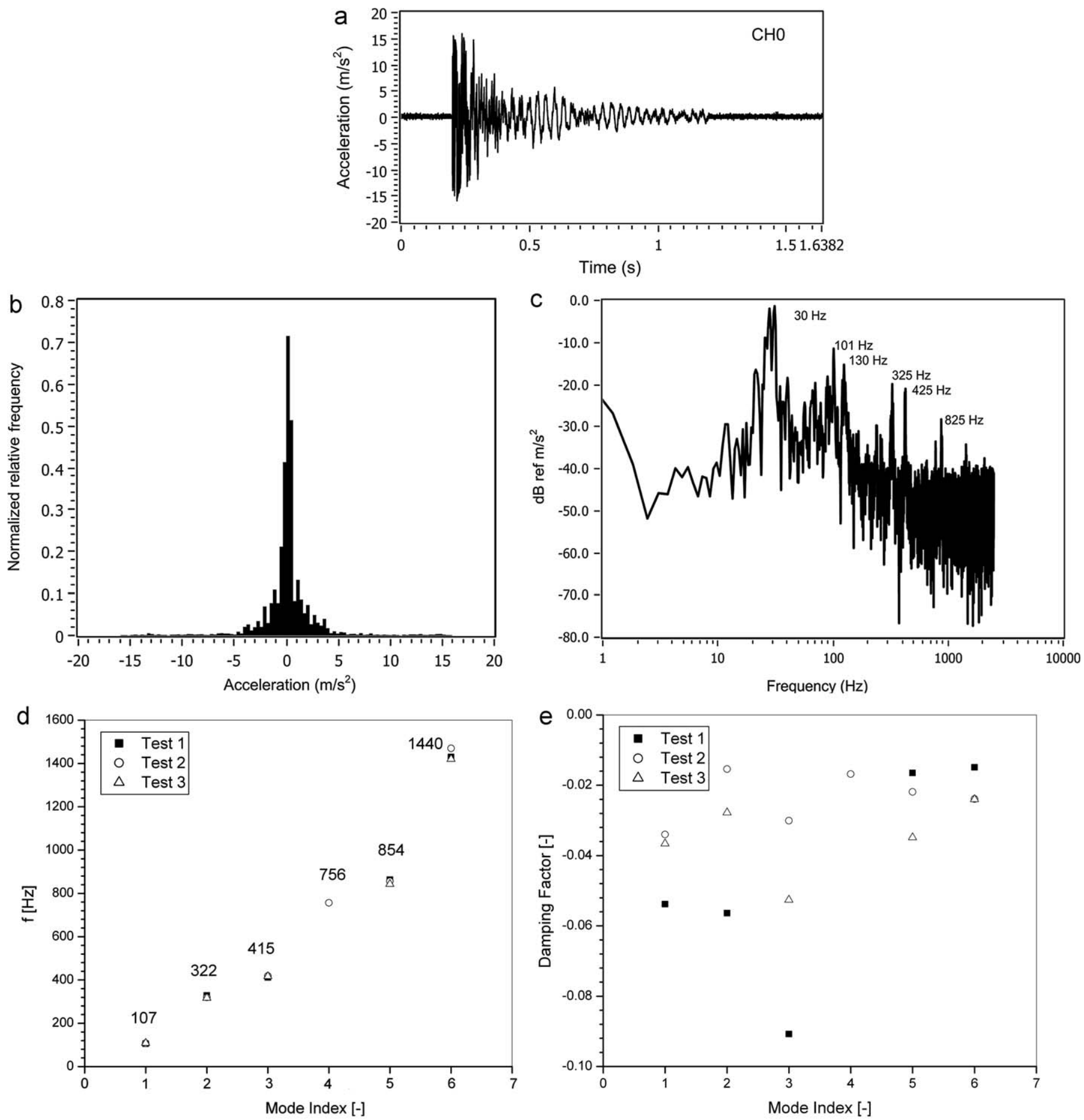

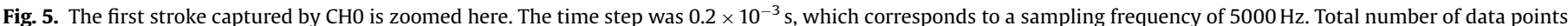
in a sample was $16384=2^{14}$. The frequency resolution is $1.22 \mathrm{~Hz}$.

without flow vanes, respectively. The spectrograms (Hanning window 64 samples, 512 frequency bins and 32 time bins) of the sound signal show the characteristics of various flow regimes in the time-frequency domain during operation of the mockup. The flow parameters, which are given for each picture, supplement the spectrograms and characterize the selected flow regimes. For no-flow conditions a very stable $5 \mathrm{kHz}$ component was captured. The source of this component is not known, but since this frequency coincides with the sampling frequency of the acceleration measurements, it could not be recorded in those tests. A hammer stroke can be easily identified in Fig. 10b. Resonance vibrations with frequencies from 1 to $10 \mathrm{kHz}$ are dampened within about $0.1 \mathrm{~s}$. The large magnitudes of the STFT coefficients, which are spread over the full frequency domain, characterize the audible noise generated by cavitation (Fig. 11b). The loud tones at 1.2 and $2.5 \mathrm{kHz}$ (whistling sound) can also be identified in the spectrograms (Fig. 11c and d). These resonance frequencies indicate that the mock-up with the flow vanes was operated under extreme conditions. In addition, as the flow rate was relatively high (about $7.5 \mathrm{l} / \mathrm{s}$ ) and the pressure of the cover gas 
a

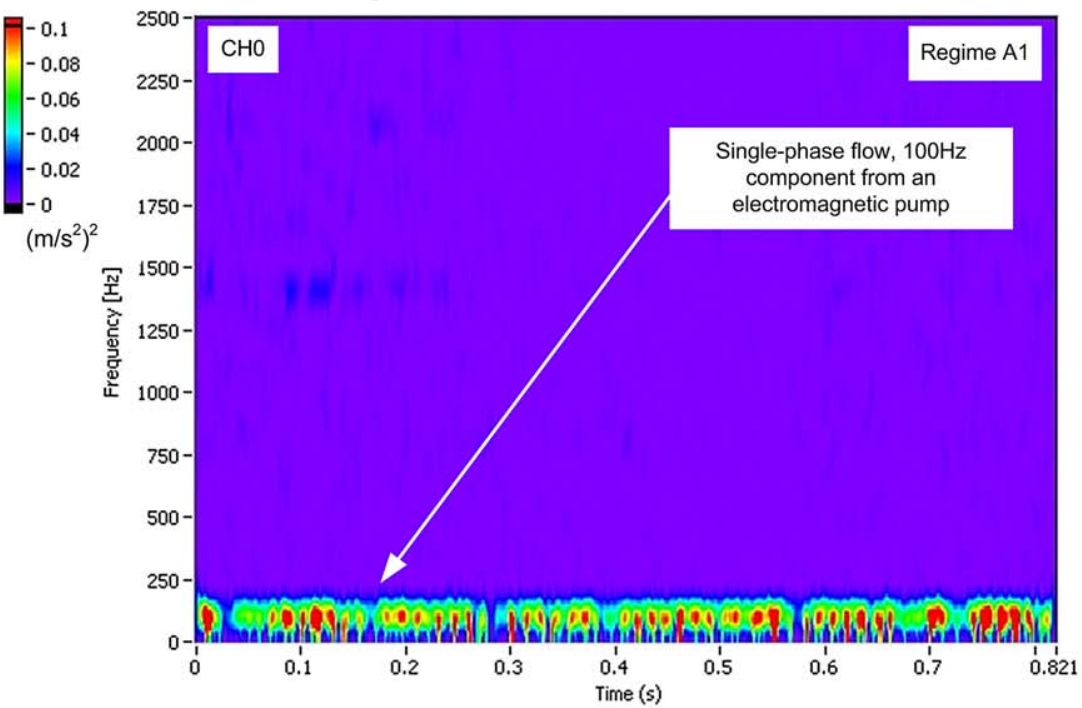

b

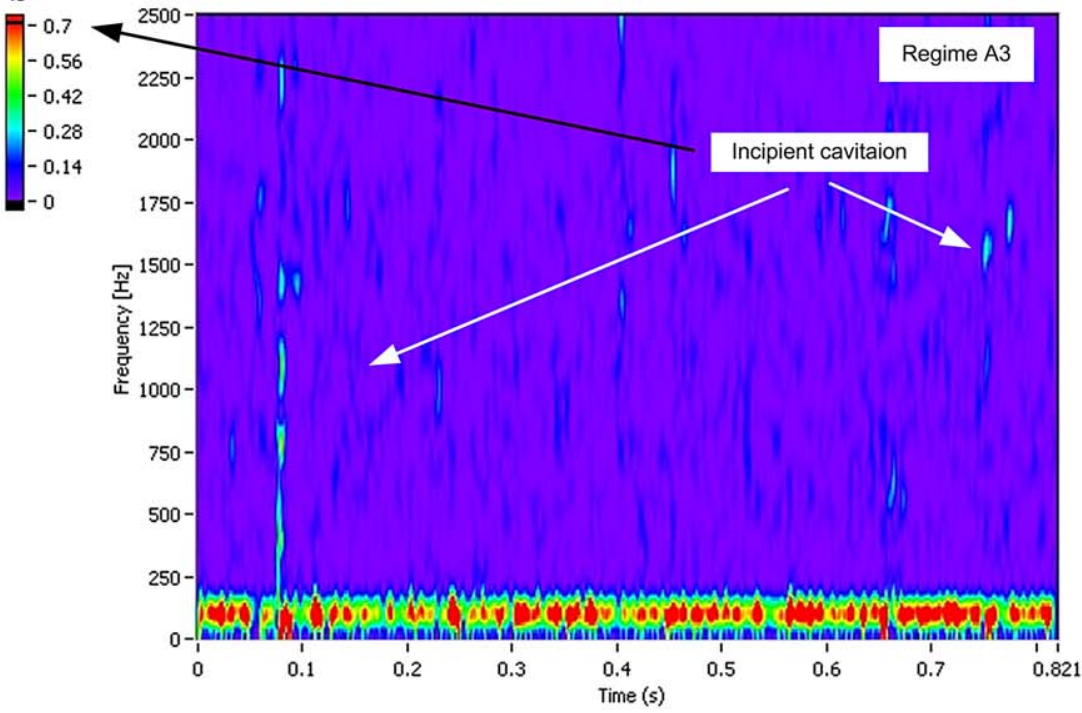

C

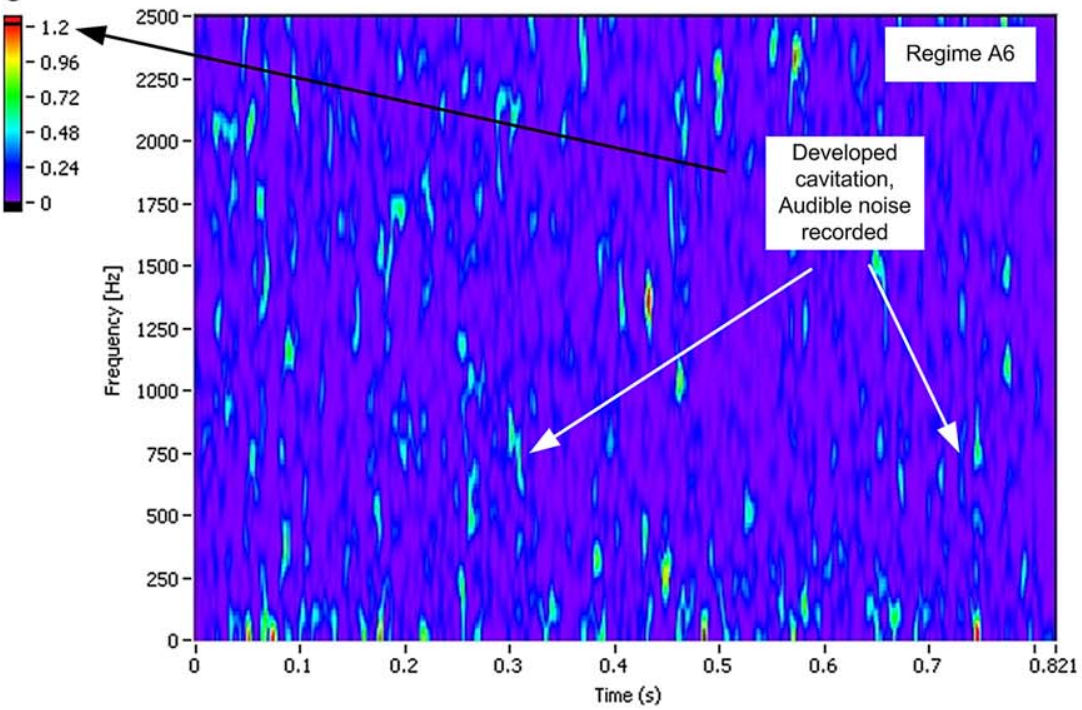

Fig. 6. Configuration without flow vanes: STFT (CHO) spectrograms for single-phase (a), incipient cavitation (b) and developed cavitation flow regimes (c). 
a

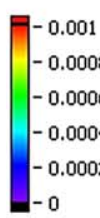

$\left(\mathrm{m} / \mathrm{s}^{2}\right)^{2}$

b

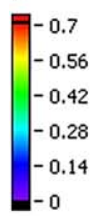

-0.7
-0.56
-0.42
-0.28
-0.14
-0

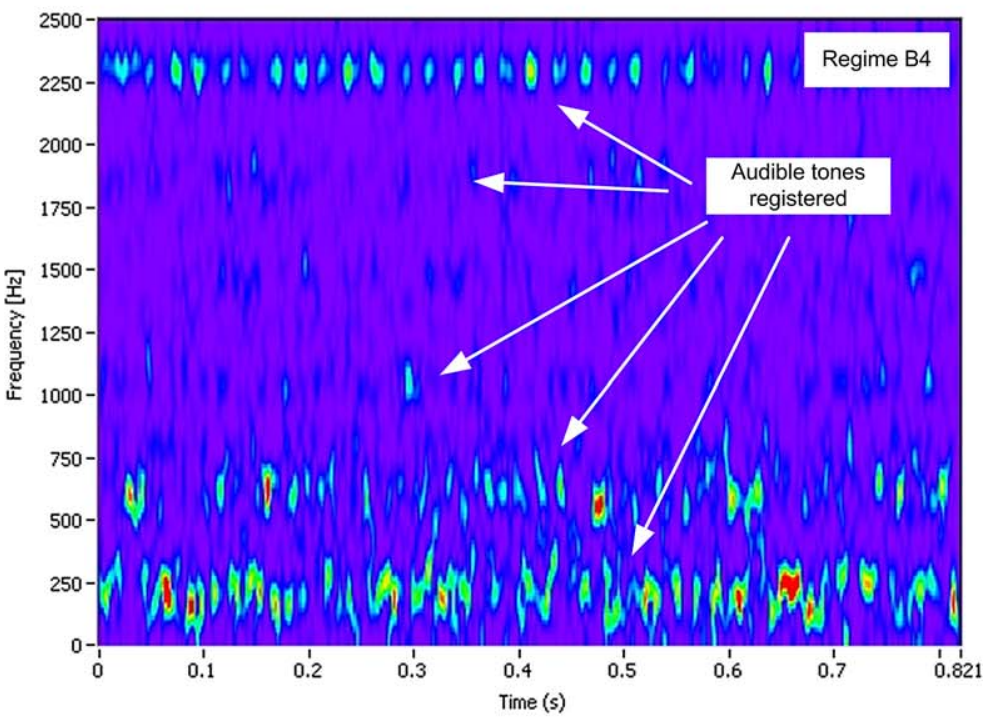

C

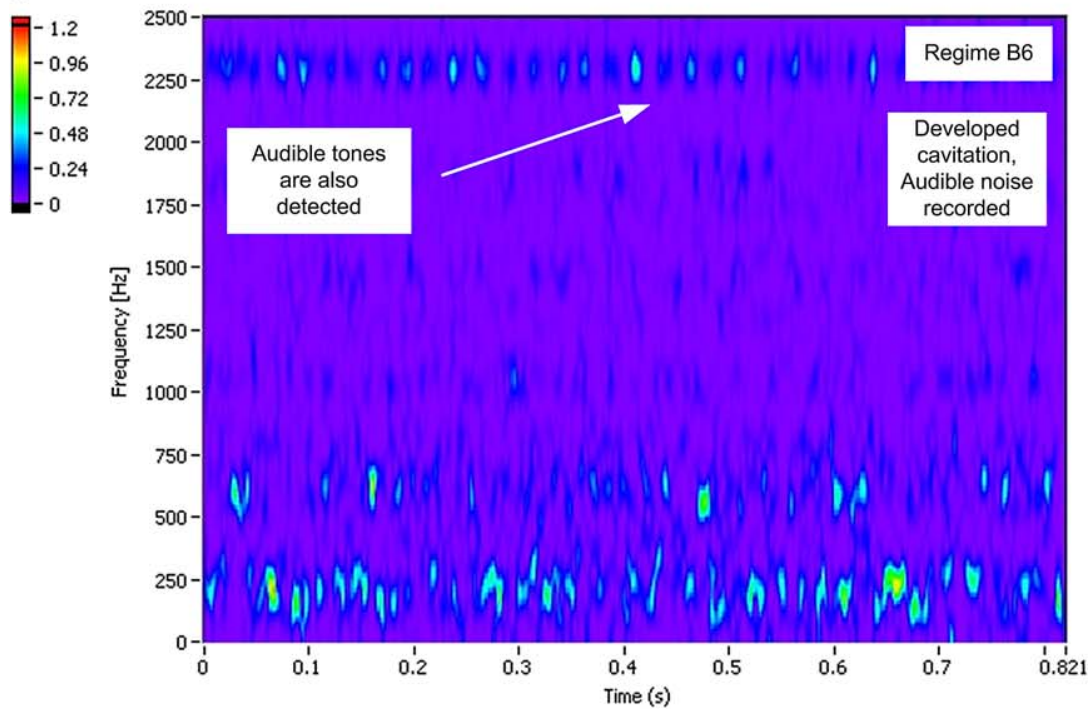

Fig. 7. Configuration with flow vanes: STFT ( $\mathrm{CHO}$ ) spectrograms for single-phase (a and b) and developed cavitation flow regimes (c). 


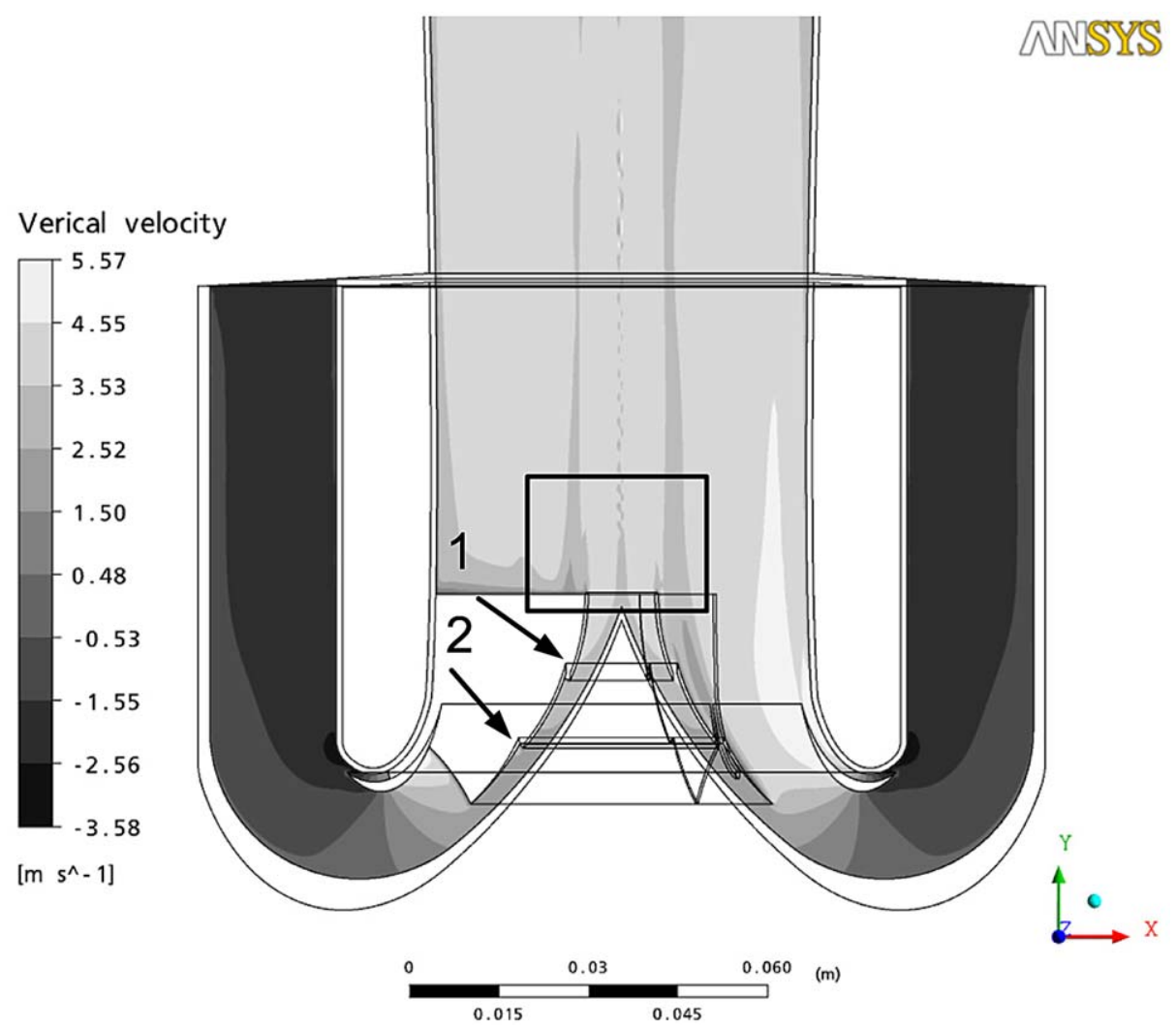

Fig. 8. Velocity field obtained from RANS simulation.

was low, a cavitation noise is superimposed onto the signal and can be identified by the larger magnitudes of the STFT coefficients.

These results indicate critical values of operating parameters have been reached. This was expected as a prior dynamic analysis by Samec et al. [6] pressure variations from a CFD analysis to a structural FEM model indicated that resonance in the vanes was likely to lead to high cycle fatigue at $200 \mathrm{~Hz}$ and failure after a few hours of operation due to a weakness in the design of the flow vanes. Thus any further increase of the flow rate and decrease of the operating pressure, in particular a prolonged operation under critical conditions, are likely to lead to a failure of the flow vanes and/or the welds that hold them. Since, the mock-up with the existing flow vanes design cannot be operated safely at high flow rates and low pressures in the system over the long term, this design aspect must be strengthened in the future. However, for the short duration of the test it was estimated that the design of the flow vanes would be adequate. Furthermore, the resultant of all hydraulic forces on the flow vanes tends to sweep them away from the fragile BEW. These forces may also cause failure of the welds.

\subsection{Strain measurements}

As mentioned in the previous section, a hypothetical failure of the target during the hydraulic test could result from the excitation of a resonance of the structure by the turbulence or the cavitation in the flowing liquid metal. Hence two sets of strain gauges were set up to monitor critical locations, as shown schematically by type 1 and 2 gauges indicated by the numbers 1 and 2 in Fig. 12.

The type 1 gauges were positioned in four different locations, spaced by $90^{\circ}$ around the circumference of the tube, so as to pick up bending about either of the two main bending axes. These gauges were connected to a Wheatstone half-bridge. Strain gauges on opposite sides of the tube operate as a tension/compression couple in order to increase the accuracy of the signal. The signal output by the strain gauges was twice the amplitude of the bending component of the strain, as gauges were placed on opposite sides of the bending section (pos. 1 in Fig. 13), ensuring that values are equal in magnitude but have opposite sign. The signals were subtracted in the Wheatstone bridge, resulting in $\Delta x-(-\Delta x)=2 \Delta x$ i.e. twice the amplitude of the gauge signal. The type 2 gauges, which monitor the weld, were connected to a full Wheatstone bridge and thereby measure the direct strain perpendicular to the weld.

In this manner, the bending oscillation strain about both axes could be monitored at the same time as the stresses in the critical locations on either side of the weld. This arrangement can give adequate warning before the occurrence of a failure, should the vibrations induced by the liquid metal flow approach allowable limits. These limits were determined by a critical weld connecting the interface block to the inlet tube (pos. 2 in Fig. 12). At this location the membrane stress in the tube in a direction perpendicular to the weld causes stress concentration by pulling on the weld. The value of the membrane stress in the tube must be limited to $65 \mathrm{MPa}$ to avoid damaging of the weld. The stresses were obtained form the strain using Hooke's law and a Young's modulus of $190 \mathrm{MPa}$.

A test of the accuracy of the strain gauges was carried out by hitting the filled target vertically with a hammer to induce a vertical oscillation. The results obtained from the strain gauges are shown in Fig. 13. The vertical bending oscillation is quite clearly picked up in the form of a dampened oscillation with a base frequency of $30 \mathrm{~Hz}$ (the same peak is found in acceleration data from $\mathrm{CHO}$ and $\mathrm{CH} 1$, see Fig. $5 \mathrm{c}$ ). The horizontal pair and the strain gauge at the edge of the weld also pick up the oscillation, demonstrating that the strain gauge response is satisfactory. 

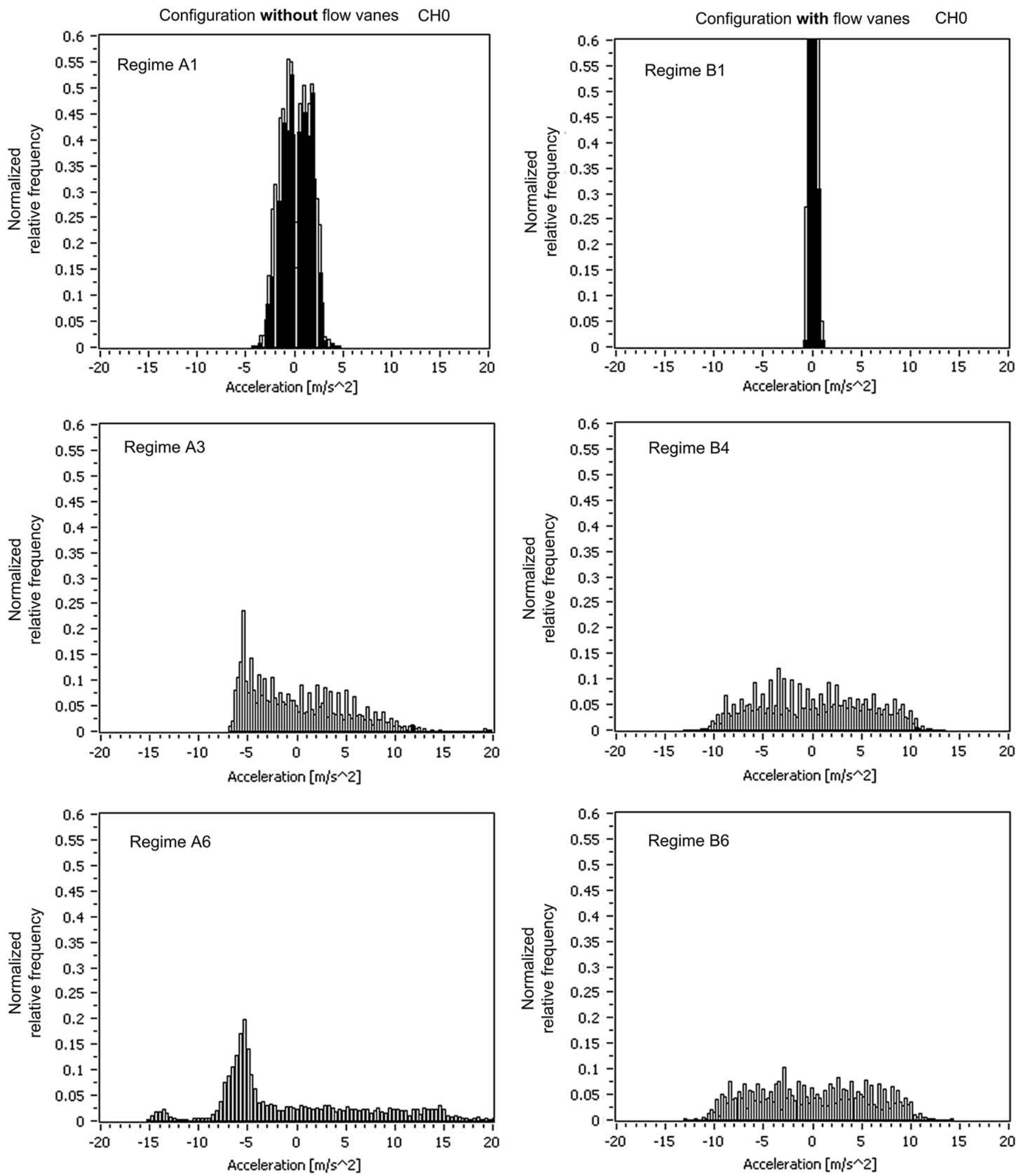

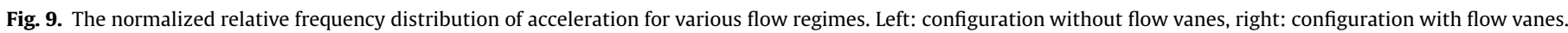

The magnitude of the base frequency is at least a factor of two below the calculated value, approximately $60 \mathrm{~Hz}$, depending on assumptions [6]. It would therefore appear that the support afforded to the target by the test rig is not as stiff as expected. The truss structure holding the target (Fig. 4), which is relatively tall, has enough flexibility to lower the frequency of the natural bending mode of the target significantly.

Fig. 14 shows a typical output in a high flow rate regime (B6); maximum stresses around the welds at $5 \mathrm{MPa}$ are well below allowable limits. The effect of increasing the flow rate is to 


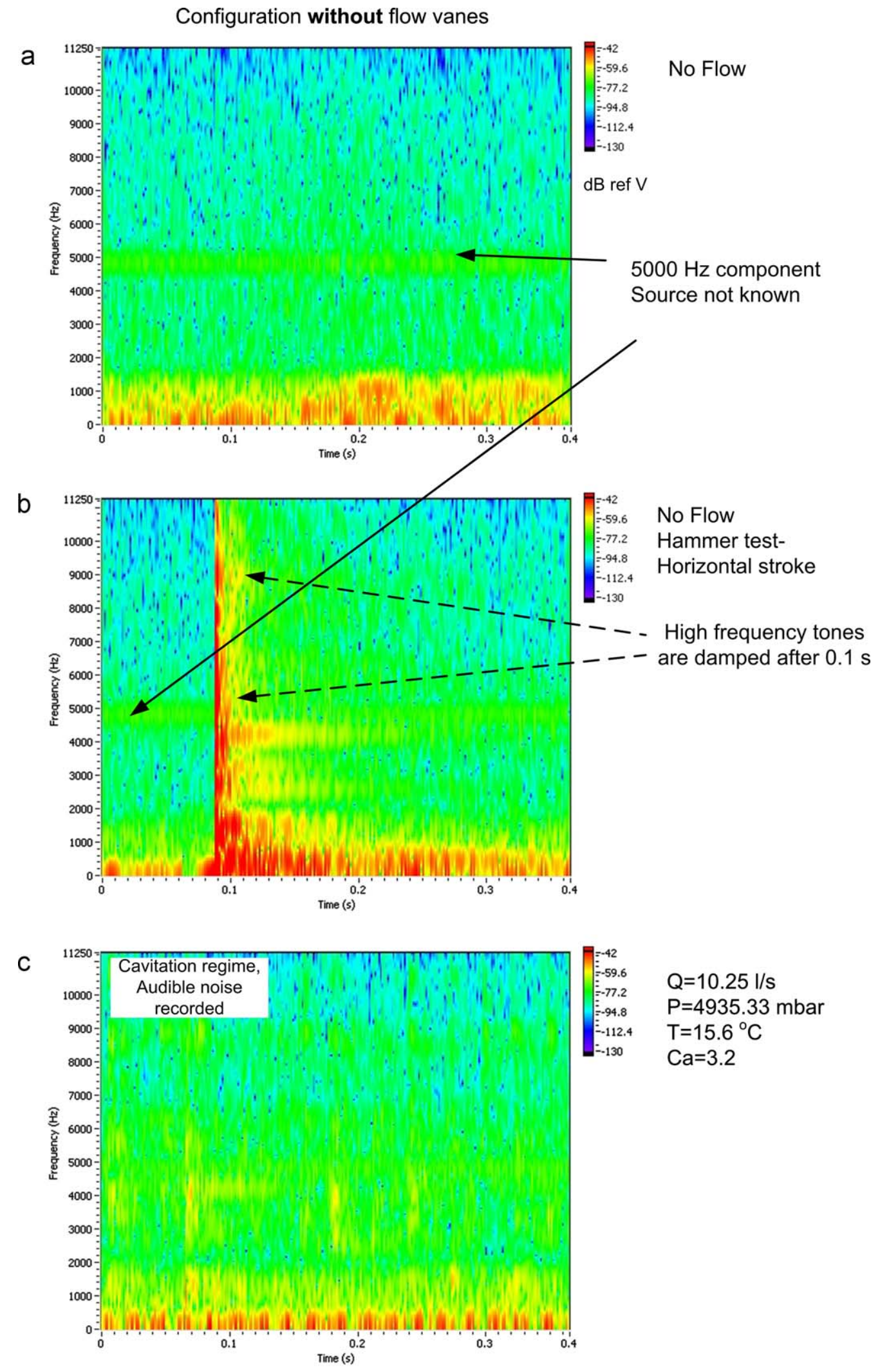

Fig. 10. Spectrograms of the Short-Time Fourier Transform applied on sound data for configuration without flow vanes.

straighten out the bent pipe section of the inlet part, in the same manner as a coiled-up hose is straightened out when opening the flow. On the other hand, there is no significant lateral stress or lateral vibration, as all major instabilities in the flow are caused by the fluid entering the target from below. Thus bending is primarily restricted to the vertical plane through the target axis leading 


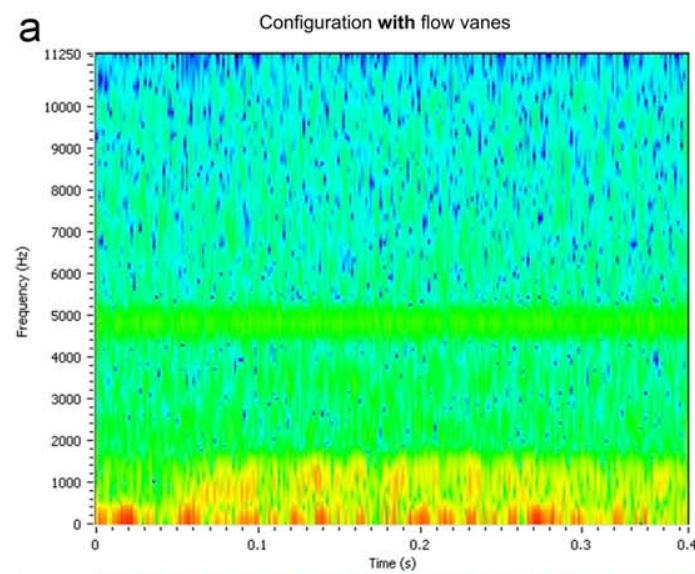

No Flow
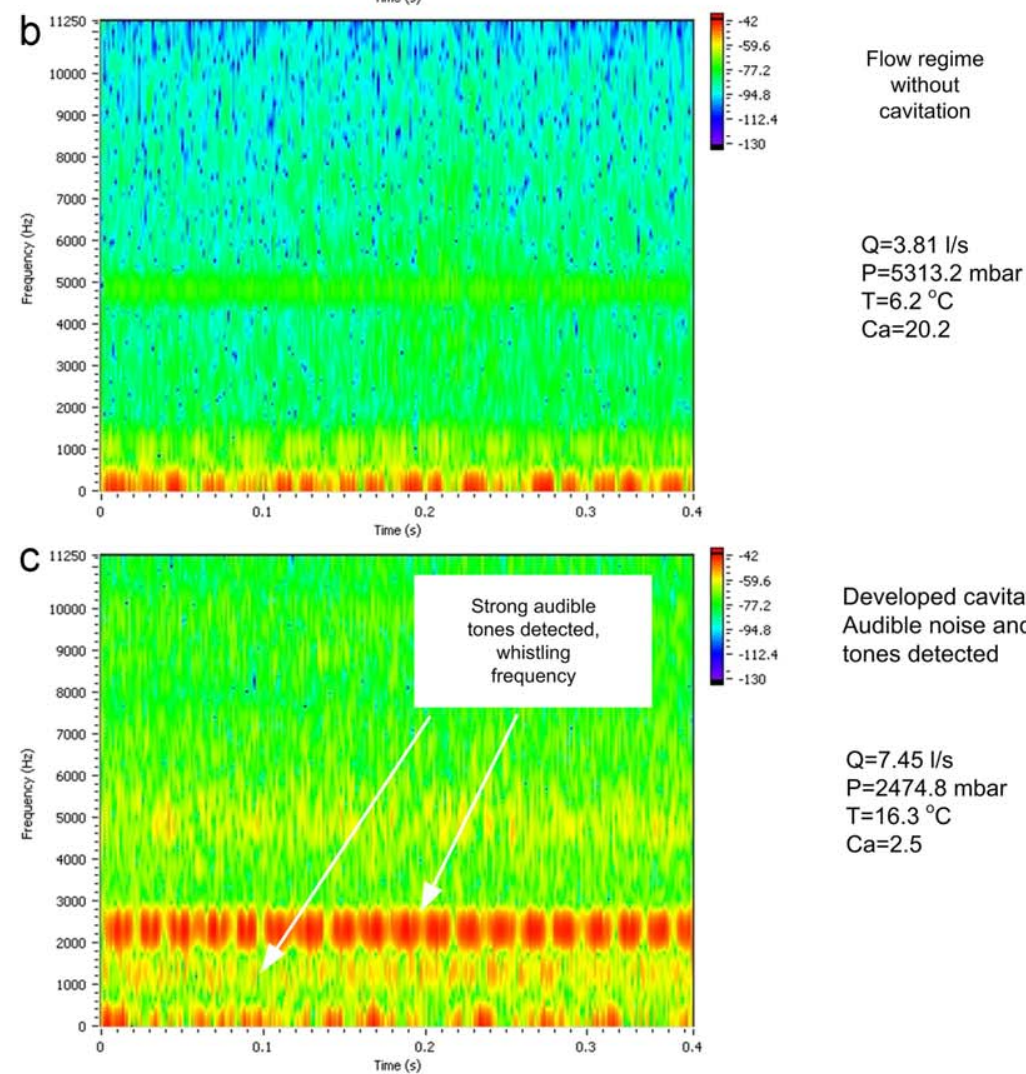

Developed cavitation,

Audible noise and

tones detected

\author{
$\mathrm{Q}=7.45 \mathrm{I} / \mathrm{s}$ \\ $\mathrm{P}=2474.8 \mathrm{mbar}$ \\ $\mathrm{T}=16.3^{\circ} \mathrm{C}$
}

$\mathrm{Ca}=2.5$

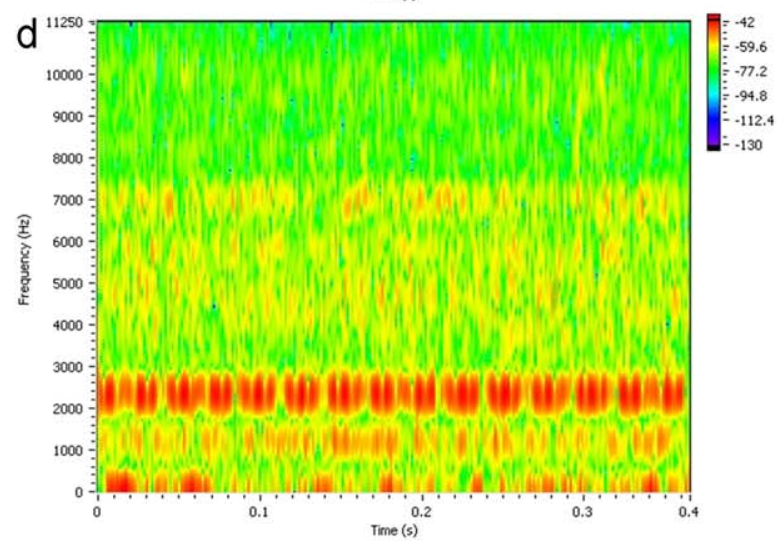

Developed cavitation,

Strong audible noise and tones detected

$\mathrm{Q}=8.58 \mathrm{l} / \mathrm{s}$

$\mathrm{P}=5388.8 \mathrm{mbar}$

$\mathrm{T}=18.2^{\circ} \mathrm{C}$

$\mathrm{Ca}=4.13$

Fig. 11. Spectrograms of the Short-Time Fourier Transform applied on sound data for configuration with flow vanes.

only to stresses in the vertical plane. The graph shows twice the amplitude of the bending stress, hence the magnitude of the stress at pos. 1 (Fig. 13) is $6.5 \mathrm{MPa}$. The weld stress at pos. 2 (Fig. 12) is
$5 \mathrm{MPa}$. As predicted by the FEM analysis, the measurement shows that the stress is $25 \%$ lower in the tube adjacent to the weld than at the exit of the inlet section around the flange. 
(1) Gauges monitoring bending vibrations

(2) Gauges monitoring critical weld
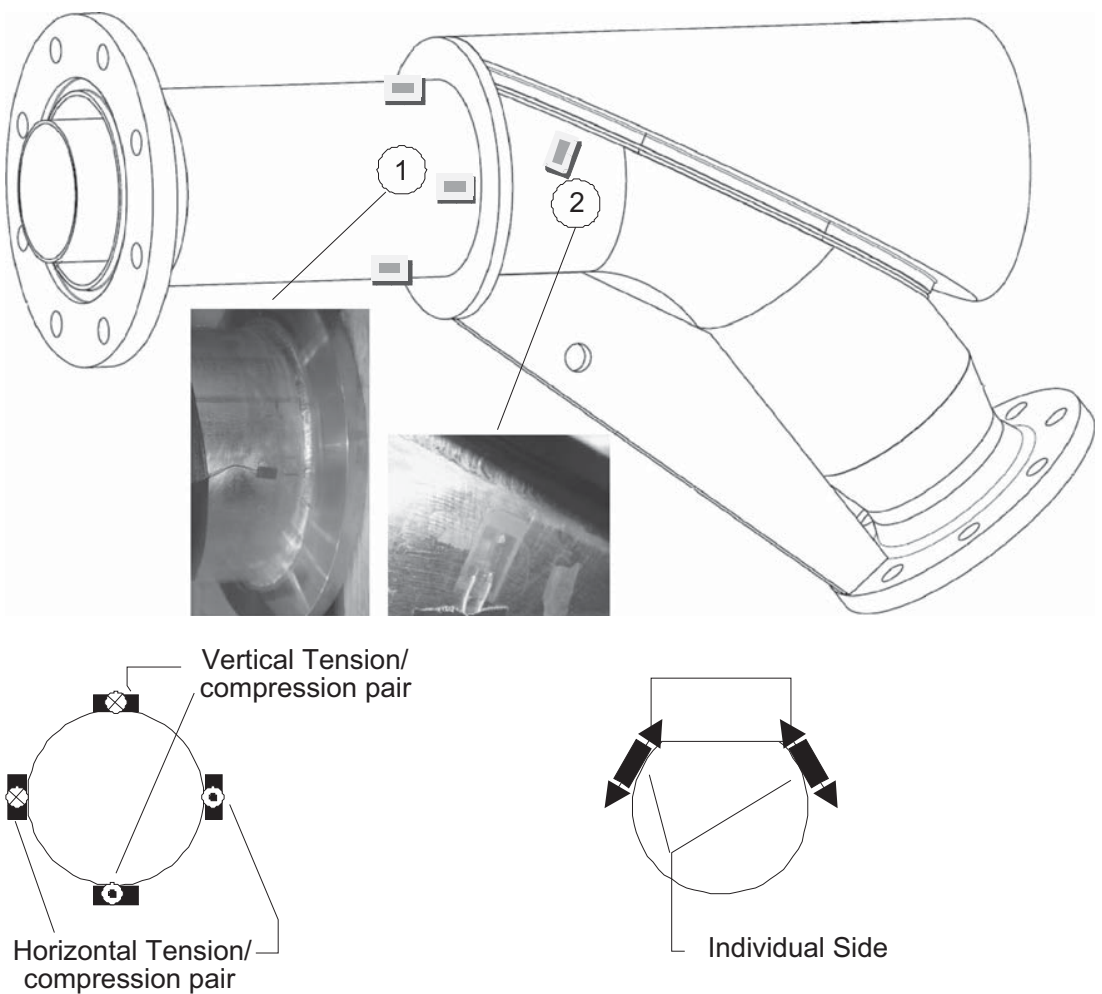

Fig. 12. Positions of the strain gauges

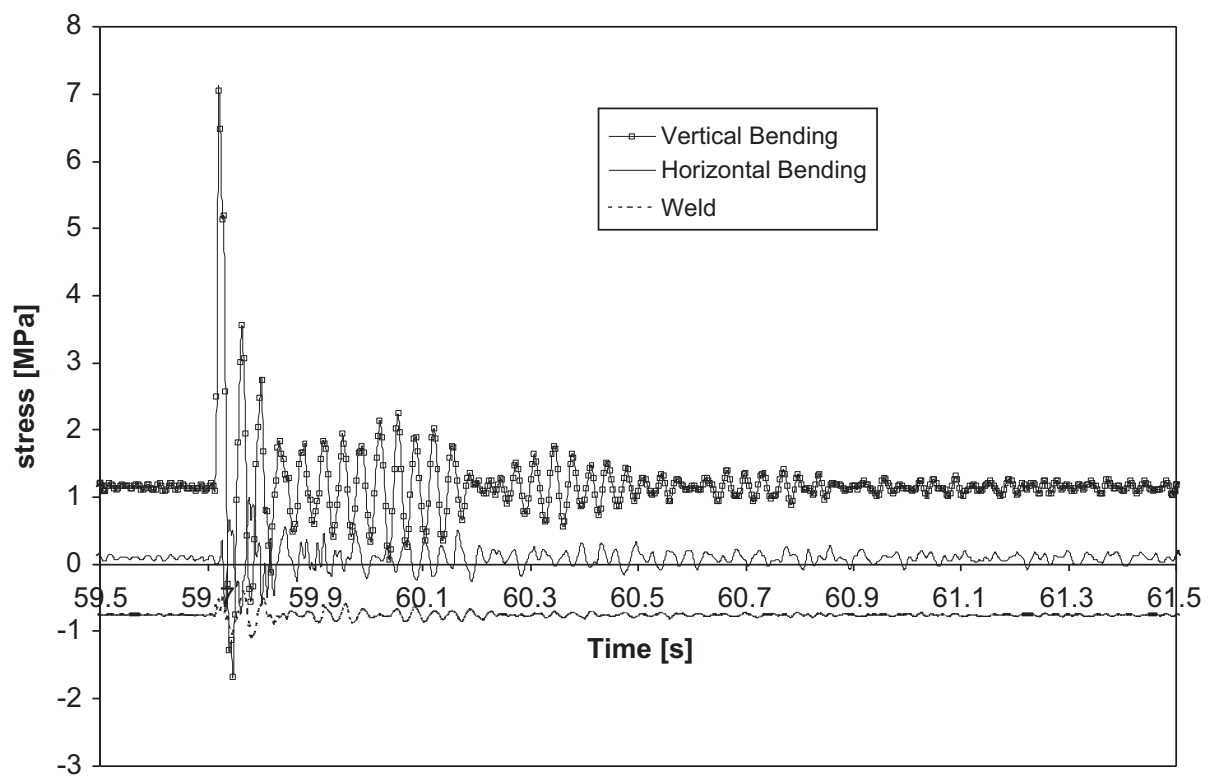

Fig. 13. Stress data during vibration test.

\section{Summary and conclusions}

The experimental results presented here show the effects of hydraulic and structural behaviour of the target mock-up under turbulent flow conditions as well as under incipient and developed cavitation. The following hydraulic and structural parameters were measured: the total hydraulic pressure loss in the mock-up, the pressure of the cover gas in the expansion tank, the acceleration of the mock-up and of the loop filled with mercury, the fluid temperatures at the mock-up inlet and outlet, the mass flow rate, the strain at various locations and sound in the laboratory. Two different configurations have been tested: with and without flow vanes. 


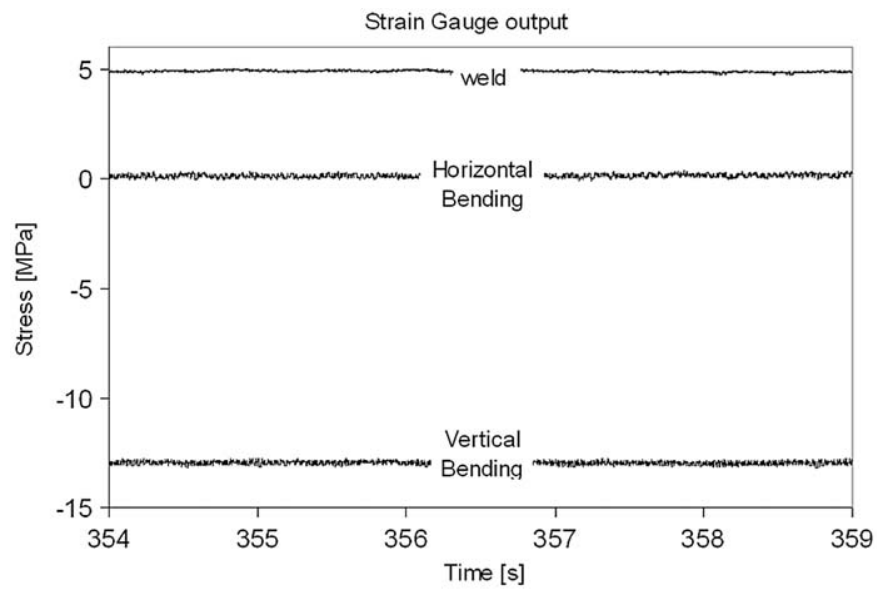

Fig. 14. Stress data during operation (regime B6).

The most important conclusions to be drawn from this test are as follows:

- The design worked satisfactorily and reached $90 \%$ of the full design flow rate (11.2 l/s versus a design value of $12.6 \mathrm{l} / \mathrm{s}$ ) with little structural vibration.

- The pressure loss in the target at less than 2 bar is remarkably low for a neutron spallation target capable of absorbing a $4 \mathrm{MW}$ beam in a very compact design; less than $15 \mathrm{~cm}$ in diameter.

- The maximum flow rate achieved without flow vanes was $11.2 \mathrm{l} / \mathrm{s}$. In order to suppress cavitation, sufficiently high pressures must be applied inside the target. The lower limit of the operating pressure could not be precisely estimated, but it is likely to be higher than 6 bar. The design static pressure is 5 bar, but the design allows the static pressure to be increased considerably, as the factor of safety (= rupture load/actual load) against pressure rupture is close to 10 . The current design static pressure is set to ensure that sufficient margin exists against boiling of the mercury when the target is under power and the LM temperature reaches a peak of $290^{\circ} \mathrm{C}$, which is well below the boiling point of $450{ }^{\circ} \mathrm{C}$ at 5 bar. Obviously, increasing the design value would benefit both margins against cavitation and boiling. The likelihood of the BEW buckling under internal pressure was investigated in ANSYS [3] using an elastic linear Eigen mode buckling analysis and the margin was found to be extremely high due to the double curvature of the window shape which has a self-stabilising effect.

- At high flow rates and low pressure, jet cavitation can occur at the outlet of narrow gaps (see Fig. 1b and c, configuration with the flow vanes). In addition, naturally-developing instabilities can be periodically triggered and may cause blades to resonate. Having considered these aspects, as well as the structural integrity of the vanes, the design can be improved.

- Structural and sound measurements can be used for detecting and studying various flow phenomena and instabilities, such as effects on the structural vibrations of the flow turbulence, incipient and developed cavitation, vortex shedding and large coherent structures.

The results of this unique and successful EURISOL mock-up test helped to validate computational results and triggered further activities regarding testing and improvement of the current design.

\section{Acknowledgements}

The authors are grateful to August Kalt and Sergej Ivanov for their valuable assistance and numerous technical contributions to the design and implementation of the experimental installation and to Werner Wagner and Friedrich Gröschel for fruitful discussions, advice and support. Fillipo Barbagallo provided very useful ancillary equipment for placing acceleration sensors and thermocouples at the decisive locations. Many thanks to Stefan Joray for his contribution regarding cooling of the loop.

We acknowledge the financial support of the European Community under the FP6 "Research Infrastructure ActionStructuring the European Research Area" EURISOL DS Project Contract no. 515768 RIDS. The EC is not liable for any use that can be made with the information contained herein.

\section{References}

[1] Internet Source, 〈http://www.eurisol.org >, 2009

[2] K. Samec, Design of the EURISOL converter target, Technical Note TM-34-0705.2007.

[3] ANSYS Inc., ANSYS CFX Solver Modelling Guide, CFX 11.0. 2007.

[4] D.R. Lide, et al., Handbook of Chemistry and Physics, 88th ed., 2008.

[5] W. Wagner, F. Groeschel, K. Thomsen, H. Heyck, MEGAPIE at SINQ, The first liquid metal taret driven by a megawatt class proton beam, J. Nucl. Mater. 377 (2008) 12.

[6] K. Samec, R.Ž. Milenkovic, S. Demetjevs, M. Ashrafi-Nik, A. Kalt, 2009. Design of a compact high power neutron source-The EURISOL converter target, Nucl. Instr. and Meth. A, in press, doi:10.1016/j.nima.2009.04.052

[7] R.Ž. Milenkovic, S. Dementjevs, K. Samec, A. Flerov, E. Manfrin, K. Thomsen, Wavelet analysis of experimental results for coupled structural-hydraulic behavior of the EURISOL target mock-up, Nucl. Instr. and Meth. A, submitted for publication.

[8] R.Ž. Milenković, B. Sigg, G. Yadigaroglu, Bubble clustering and trapping in large vortices. Part 1: triggered bubbly jets investigated by phase-averaging Int. J. Multiphase Flow 33 (2007) 1088.

[9] I.E. Idelchik, Handbook of Hydraulic Resistance, Russian version, 1975. 